\title{
Additive Manufacturing for Highly Efficient Window Inserts
}

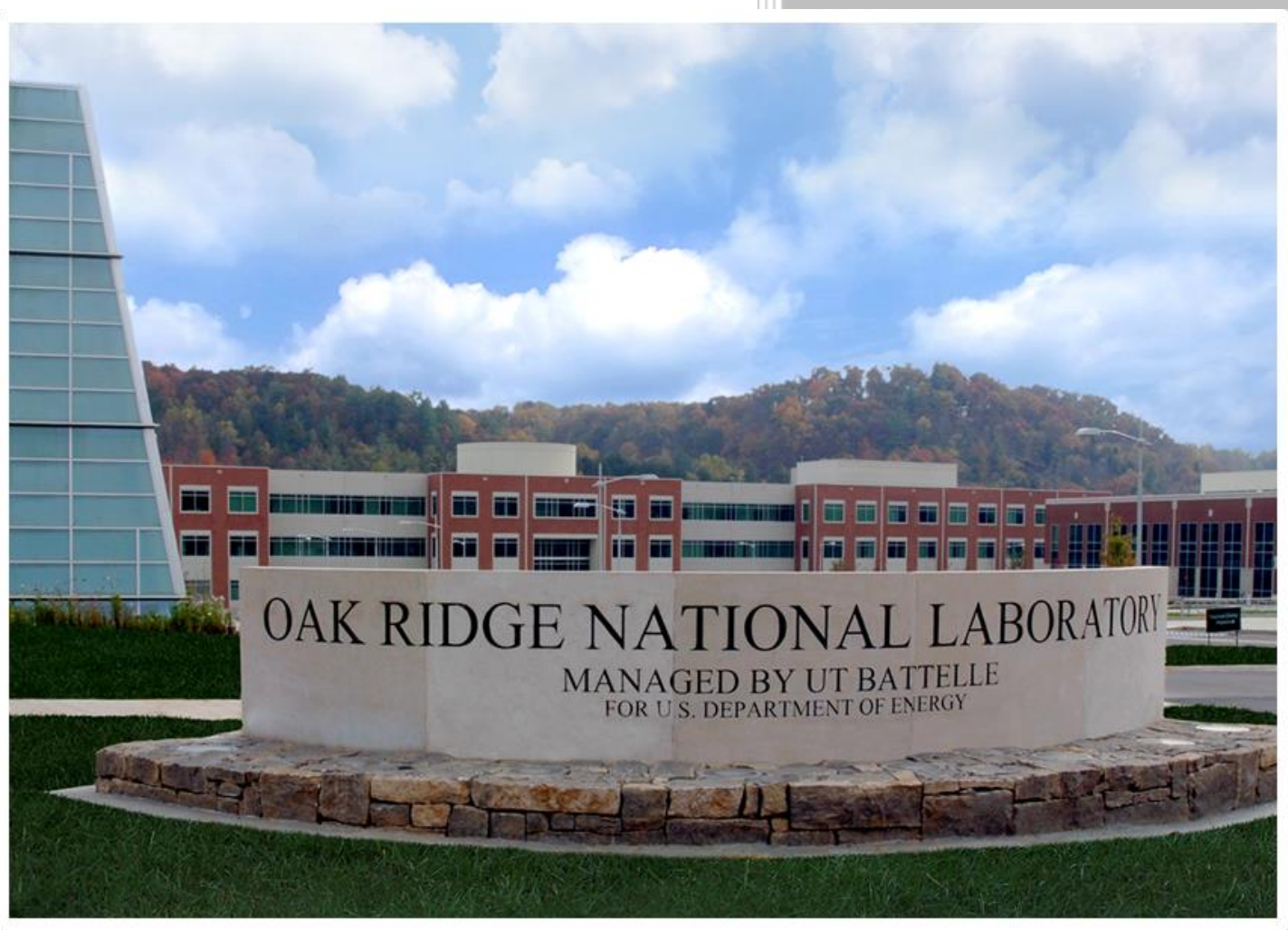

Brian Post

Peng Liu

Phillip Chesser

Alex Roschli

Lonnie Love

April 13, 2018

Approved for Public Release.

Distribution is Unlimited. 


\section{DOCUMENT AVAILABILITY}

Reports produced after January 1, 1996, are generally available free via US Department of Energy (DOE) SciTech Connect.

Website http://www.osti.gov/scitech/

Reports produced before January 1,1996, may be purchased by members of the public from the following source:

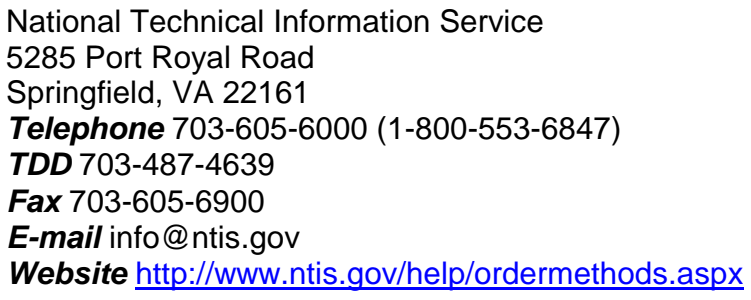

Reports are available to DOE employees, DOE contractors, Energy Technology Data Exchange representatives, and International Nuclear Information System representatives from the following source:

Office of Scientific and Technical Information

PO Box 62

Oak Ridge, TN 37831

Telephone 865-576-8401

Fax 865-576-5728

E-mail reports@osti.gov

Website http://www.osti.gov/contact.html

This report was prepared as an account of work sponsored by an agency of the United States Government. Neither the United States Government nor any agency thereof, nor any of their employees, makes any warranty, express or implied, or assumes any legal liability or responsibility for the accuracy, completeness, or usefulness of any information, apparatus, product, or process disclosed, or represents that its use would not infringe privately owned rights. Reference herein to any specific commercial product, process, or service by trade name, trademark, manufacturer, or otherwise, does not necessarily constitute or imply its endorsement, recommendation, or favoring by the United States Government or any agency thereof. The views and opinions of authors expressed herein do not necessarily state or reflect those of the United States Government or any agency thereof. 
ORNL/TM-2018/484

CRADA/NFE-16-06375

Energy and Transportation Sciences Division Advanced Manufacturing Office

\title{
Additive Manufacturing for Highly Energy Efficient Window Inserts
}

\author{
Authors \\ Brian Post \\ Peng Liu \\ Phillip Chesser \\ Alex Roschli \\ Lonnie Love
}

Date Published:

April 13, 2018

\author{
Prepared by \\ OAK RIDGE NATIONAL LABORATORY \\ Oak Ridge, Tennessee 37831-6283 \\ managed by \\ UT-BATTELLE, LLC \\ for the \\ US DEPARTMENT OF ENERGY \\ under contract DE-AC05-00OR22725
}

Approved For Public Release 


\section{CONTENTS}

PAGE

CONTENTS

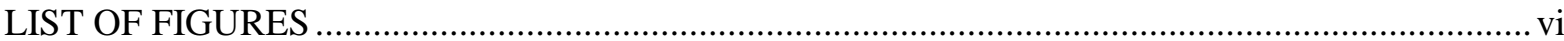

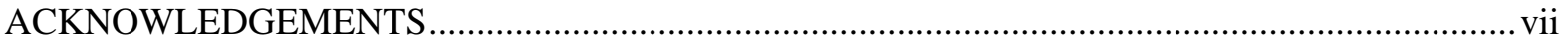

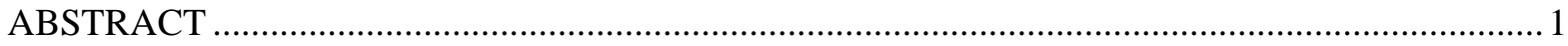

1. ADDITIVE MANUFACTURING FOR HIGHLY EFFICIENT WINDOW INSERTS ................. 1

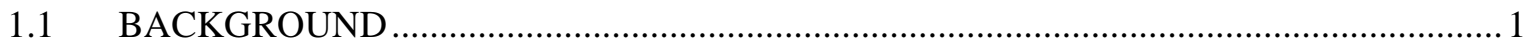

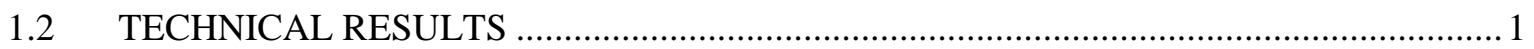

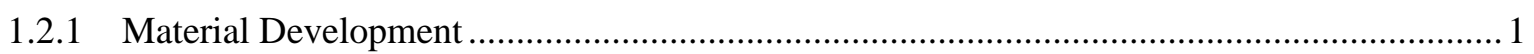

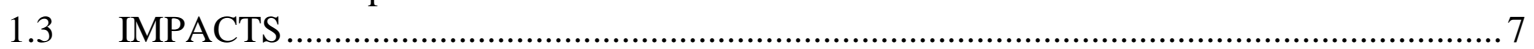

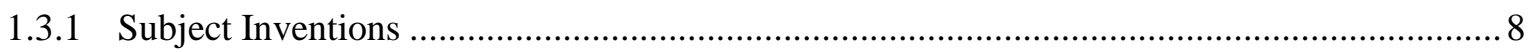

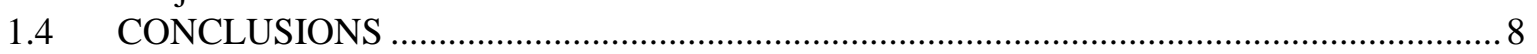

2. THE MACKINAC TECHNOLOGY COMPANY BACKGROUND ............................................. 9 


\section{LIST OF FIGURES}

Fig. 1. Morphology of ABS and $20 \mathrm{wt} \%$ carbon filled ABS composites that contain varied concentrations of hollow glass microspheres. (a) Neat ABS with 50 vol\% HGMs; (b) carbon filled ABS with 20 vol\% HGMs; (c) carbon filled ABS with 50 vol\% HGMs.

Fig. 2. Fractured tensile test specimens.

Fig. 3. Tensile Strength of Printed Syntactic ABS Foam with layer times of 20 and 40s in-plane (X) and layer to layer $(\mathrm{Z})$.

Fig. 4. Elastic Modulus of Printed Syntactic ABS Foam with layer times of 20 and 40s in-plane (X) and layer to layer $(\mathrm{Z})$.

Fig. 5. Scheme shows the expanding process of polymer-based expandable microsphere.

Fig. 6. Printed ABS with expandable microspheres. $20 \%$ carbon fiber filled (left) and no fibers (right). 


\section{ACKNOWLEDGEMENTS}

This CRADA NFE-16-06375 was conducted as a Technical Collaboration project within the Oak Ridge National Laboratory (ORNL) Manufacturing Demonstration Facility (MDF) sponsored by the US Department of Energy Advanced Manufacturing Office (CPS Agreement Number 24761).

Opportunities for MDF technical collaborations are listed in the announcement "Manufacturing Demonstration Facility Technology Collaborations for US Manufacturers in Advanced Manufacturing and Materials Technologies" posted at http://web.ornl.gov/sci/manufacturing/docs/FBO-ORNL-MDF2013-2.pdf. The goal of technical collaborations is to engage industry partners to participate in shortterm, collaborative projects within the Manufacturing Demonstration Facility (MDF) to assess applicability and of new energy efficient manufacturing technologies. Research sponsored by the U.S. Department of Energy, Office of Energy Efficiency and Renewable Energy, Advanced Manufacturing Office, under contract DE-AC05-00OR22725 with UT-Battelle, LLC. 


\begin{abstract}
ORNL partnered with the Mackinac Technology Company to demonstrate how additive manufacturing and material development can be used to create energy efficient window inserts for retrofit in pre-existing buildings. The materials used for the manufacture of the frames were closely examined. Hollow particle-filled syntactic foam and low-density polymer composites formed by expandable microspheres were explored as the materials used to additively manufacture the frames of the inserts. It was concluded that low-cost retrofit window inserts in custom sizes could be fabricated using large-scale additive manufacturing using syntactic and expanded foams developed and tested through this project. However, it was determined that the resolution and multi-material capabilities of the BAAM system in its current state were not sufficient to create prototypes for end use.
\end{abstract}

\title{
1. ADDITIVE MANUFACTURING FOR HIGHLY EFFICIENT WINDOW INSERTS
}

This phase I technical collaboration project (MDF-TC-2016-105) was begun on October 7, 2016 and was completed on December 29, 2017. The collaboration partner, The Mackinac Technology Company, is a small business that has developed a transparent glazing material which allows $90 \%$ of sunlight to pass through while reflecting ultraviolet and infrared energy, dramatically improving the insulation value of retrofit windows. This project seeks to demonstrate the viability of Additively Manufactured (AM) window frames which support the novel material film, and to reduce the cost to produce retrofits to pre-existing building structures.

\subsection{BACKGROUND}

The Mackinac Technology Company is a small-medium enterprise (SME), which produces low-e polymer retrofit window inserts that significantly improve a building's energy efficiency without having to spend the time and money to completely replace all windows. Since there are many shapes and sizes of already existing windows, additive manufacturing is a good fit for this technology because of AM's ability to quickly and easily fabricate unique/individualized shapes. The partner's immediate manufacturing challenge was creating many different sizes and shapes of their window inserts.

The objective of this project is to develop processes that meet the required cost and production rates of window frames with low emissivity (low-e) polymer films. This included the identification and evaluation of polymers compatible with the low e-polymer films, the structural properties required to perform in the intended application, the modification of materials to ensure printability of the frames, and the production of prototype frames to test the chosen methodology.

\subsection{TECHNICAL RESULTS}

\subsubsection{Material Development}

ORNL was able to identify and evaluate polymers compatible with low-e polymers, and extruded window frames of the selected material were created. Details of the materials explored are below.

\subsubsection{Hollow Particle-Filled Syntactic Foam}


Hollow particle-filled composites, called syntactic foams, are classified as closed-cell foams. Enclosing porosity inside thin stiff shells of particles provides significant weight reduction and a reinforcing effect. The incorporation of an additional phase may be directed by the desire of obtaining a specific set of properties, which may not be limited to mechanical properties. The incorporation of hollow particles into the polymer matrix is achieved by mechanically mixing the materials at the temperature that the polymer matrix flows. Figure 1 shows the morphology of ABS and ABS composites that contain varied concentrations of hollow glass microspheres.
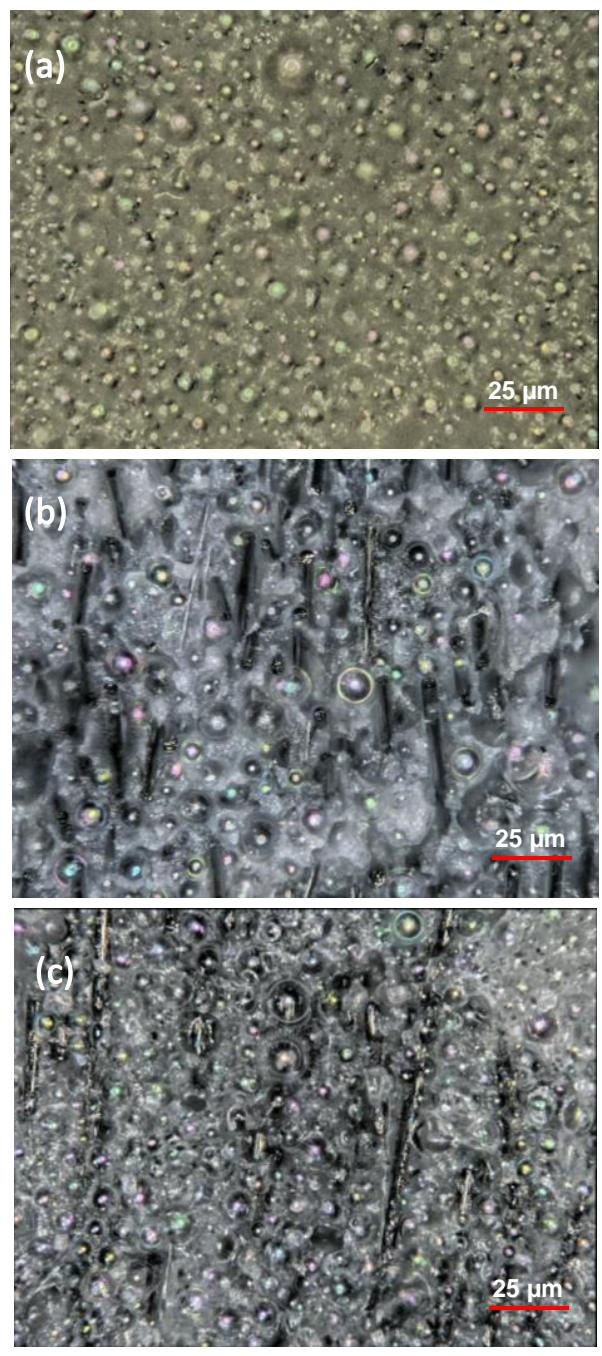

Fig. 1. Morphology of ABS and 20 wt $\%$ carbon filled ABS composites that contain varied concentrations of hollow glass microspheres. (a) Neat ABS with 50 vol\% HGMs; (b) carbon filled ABS with 20 vol\% HGMs; (c) carbon filled ABS with 50 vol\% HGMs.

Hollow glass microspheres (HGM) present different properties and have been tested in the trials. HGMs are differentiated by their bulk density, particle size, crush strength (dominated by the sphere wall thickness), and surface characteristics (a surface treatment or coating can be employed for enhancing the compatibility with the polymer matrix or promoting the flow of HGMs in the polymer matrix).

Blends of ABS, carbon fiber, and HGM's were identified and iterated to determine printability in the BAAM system, and a selection of a specific formulation was made for its excellent printability 
characteristics. Details of the formulation are listed below:

\section{Syntactic Foam Formulation:}

$50 \%$ (by vol) glass spheres (= 33\% by wt)

$10 \%$ (by wt) carbon fiber

Density: $\sim 0.8 \mathrm{~g} / \mathrm{cm}^{3}$

To evaluate the mechanical performance of the syntactic foam frames, hexagon shaped test articles were printed and material test coupons were fabricated at two different layer times: $20 \mathrm{~s}$ vs. $40 \mathrm{~s}$. Mechanical performance in $\mathrm{Z}$ is a function of the substrate (previous layer) temperature at the application of the additional layer, therefore, layer time is directly related to the $\mathrm{Z}$ strength of the material and can be a critical factor in determining the maximum size of the print. Dog-bone specimens (ASTM D638 Type 1) were machined in both printing (x) and interlayer (z) directions and the samples were tensile tested following ASTM standard D638. Digital Image Correlation (DIC) images were collected during testing.

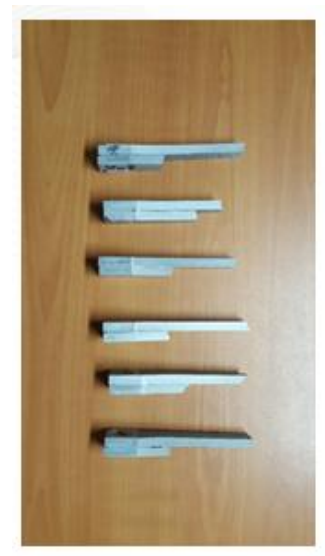

Layer Time:

$20 \mathrm{~s}$

X-direction printing

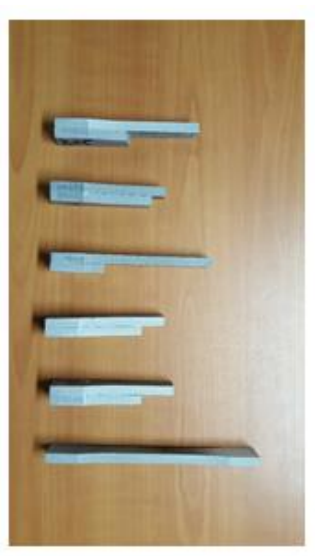

Layer Time: $20 \mathrm{~s}$ Z-direction printing

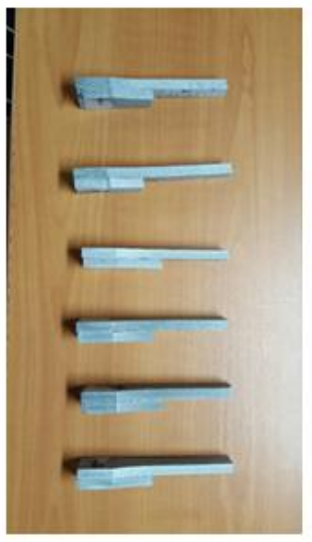

Layer Time: $40 \mathrm{~s}$ $\mathrm{X}$-direction printing

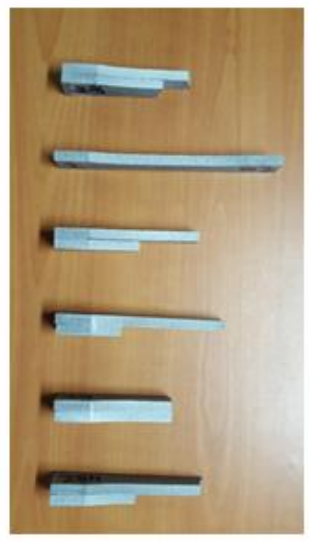

Layer Time: $40 \mathrm{~s}$ Z-direction printing

Fig. 2. Fractured tensile test specimens.

The specimens pictured in Fig 2. were fabricated and machined to ASTM specifications and then tested for tensile strength and elastic modulus. The results are shown in Figs 3 and 4. 


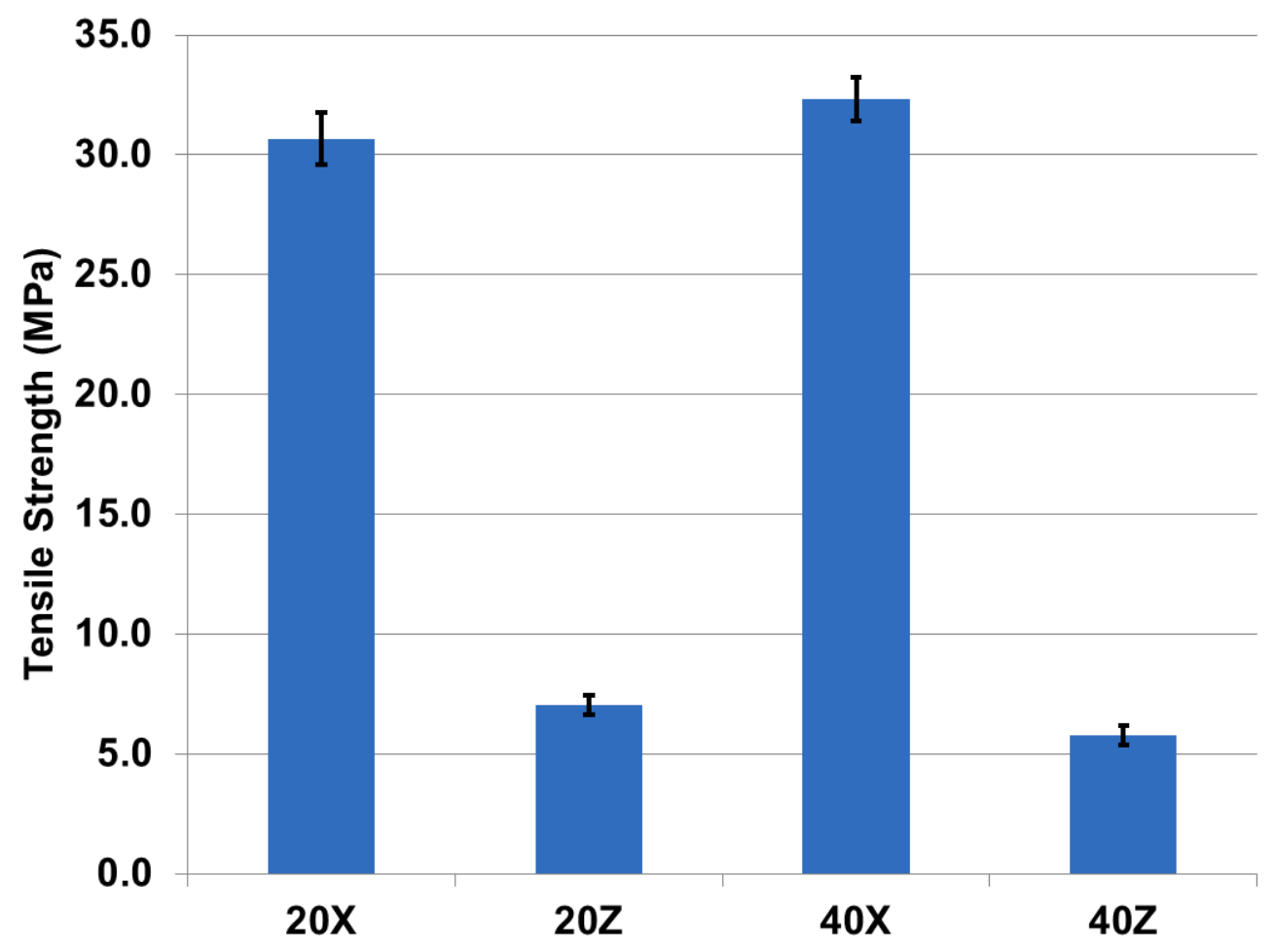

Fig. 3. Tensile Strength of Printed Syntactic ABS Foam with layer times of 20 and 40s in-plane (X) and layer to layer $(Z)$.

The tensile strength values indicate good performance in-plane and statistically indiscriminant strength values between short and long layer times. This indicates frames of multiple sizes and aspect ratios could be manufactured with this material. 


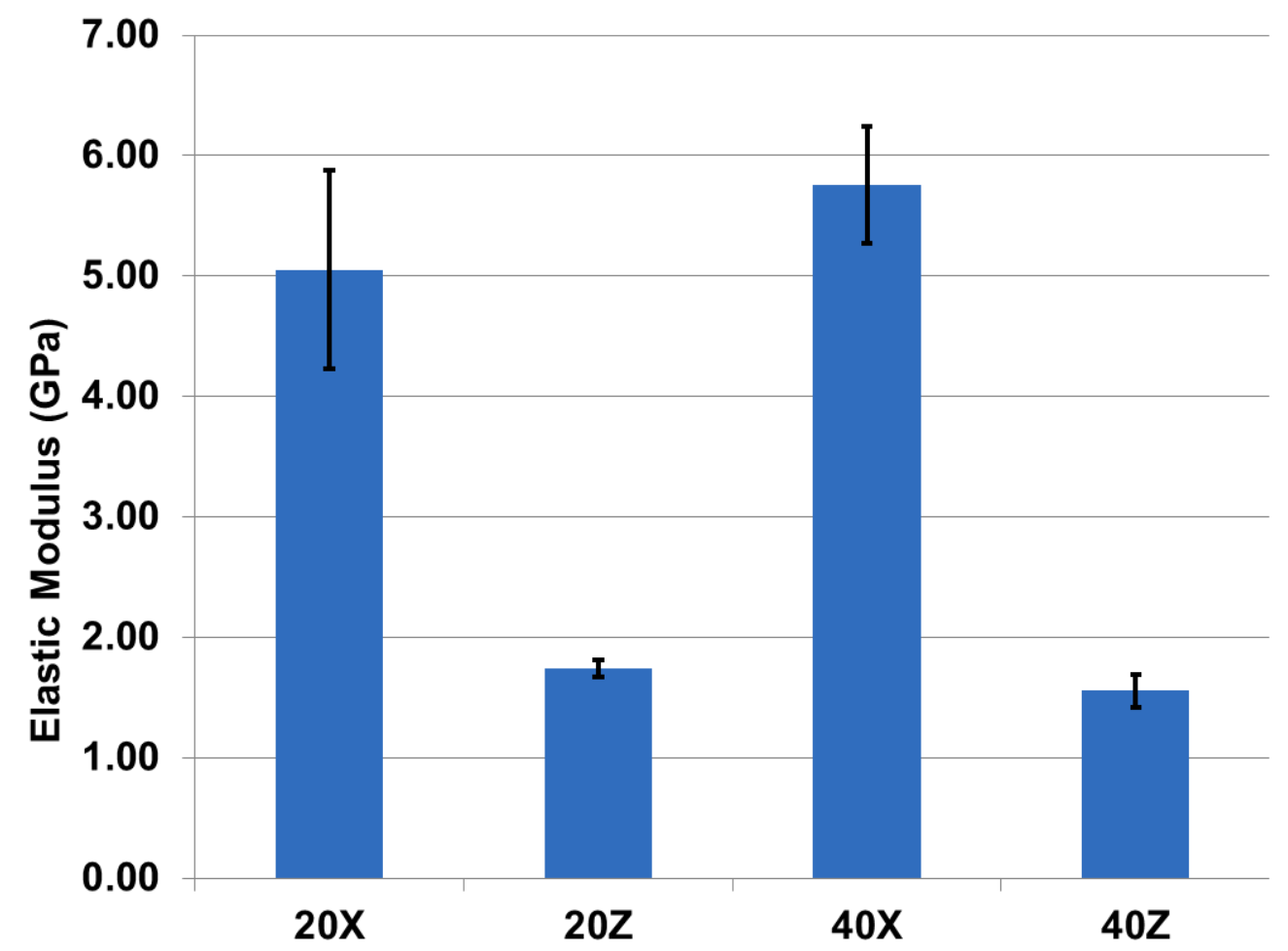

Fig. 4. Elastic Modulus of Printed Syntactic ABS Foam with layer times of 20 and 40s in-plane (X) and layer to layer $(Z)$.

The elastic modulus results also demonstrate good stiffness values that would be sufficient to support the loads of thin films tensioned across the printed frames. Suitable frame designs can leverage these properties to reduce the total material usage and optimize performance in the intended application.

The performance of the syntactic foams exceeded the requirements of the application and has a fundamental limit on achievable density; therefore non-syntactic expanded foams were also evaluated. These materials also enable better thermal performance than both standard thermoplastics and syntactic foams.

\subsubsection{Low Density Polymer Composites Formed by Expandable Microspheres}

The expandable microspheres consist of a thermoplastic polymer shell encapsulating a gas phase. Upon being heated during the printing process, the internal pressure of the expandable microsphere increases, which results in a dramatic volume increase of the microsphere.

The resulting bulk density of the material is about $0.25 \mathrm{~g} / \mathrm{cc}$. The material maintains good mechanical integrity. Fig. 5 shows the printed low-density ABS composites with expandable microspheres. Fig. 10 shows the differences in printing outcomes when the low-density polymer composites are reinforced with carbon fiber. 


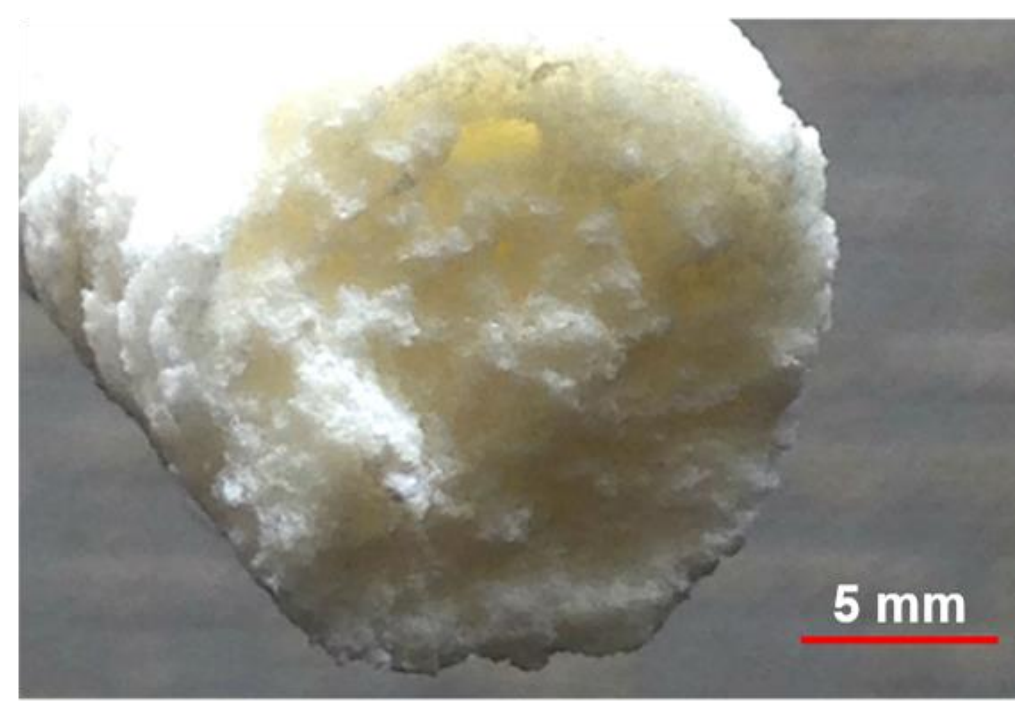

Fig. 5. Scheme shows the expanding process of polymer-based expandable microsphere.

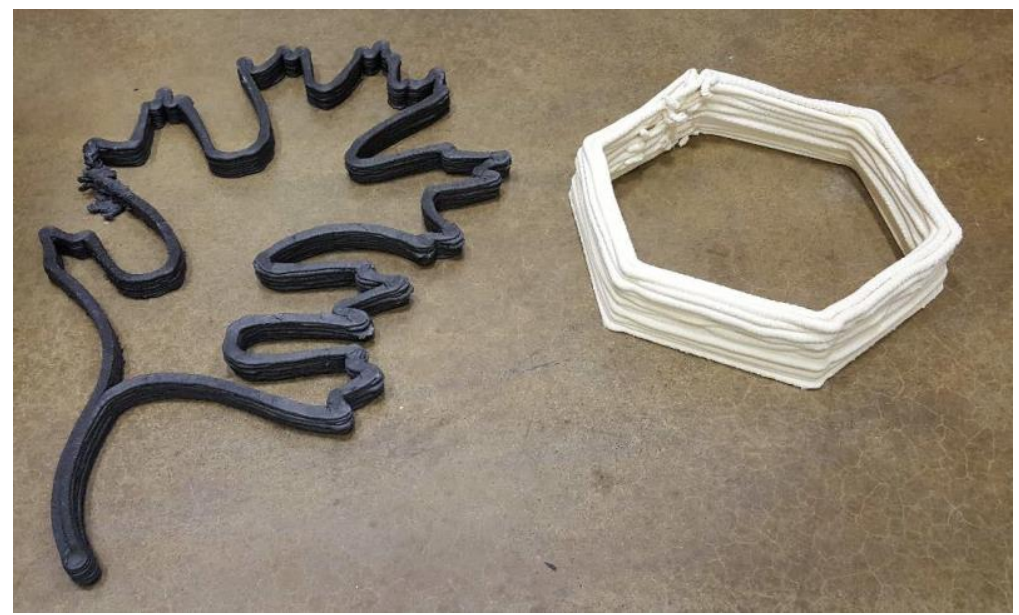

Fig. 6. Printed ABS with expandable microspheres. $20 \%$ carbon fiber filled (left) and no fibers (right).

These foams were tested using the same methodology used for the hollow particle-filled syntactic foams and the results are shown in Table 1.

\begin{tabular}{|c|c|c|c|}
\hline Material & $\begin{array}{c}\text { Elastic modulus } \\
(\mathbf{G p a})\end{array}$ & $\begin{array}{c}\text { Tensile strength } \\
(\mathbf{M p a})\end{array}$ & $\begin{array}{c}\text { Elongation at } \\
\text { break (\%) }\end{array}$ \\
\hline $\begin{array}{l}\text { Expanded } \\
\text { ABS foam }\end{array}$ & $0.5 \pm 0.1$ & $5.7 \pm 1.3$ & $52 \pm 14$ \\
\hline
\end{tabular}

Table 1. Mechanical Performance of ABS Expanded Foam in Tension.

The compressive strength performance was also characterized using the D695 - 10 standard test method for compressive properties of rigid plastics and the results are summarized in Table 2. For comparison, Neat ABS (i.e. no expandable microspheres) was also tested as a benchmark.

\begin{tabular}{|c|c|c|c|}
\hline Material & $\begin{array}{c}\text { Compressive } \\
\text { Modulus }\end{array}$ & $\begin{array}{c}\text { Compressive Strength } \\
(5 \% \text { deformation })\end{array}$ & $\begin{array}{c}\text { Ultimate } \\
\text { Compressive }\end{array}$ \\
\hline
\end{tabular}




\begin{tabular}{|l|c|c|c|}
\hline & (Gpa) & (Mpa) & $\begin{array}{c}\text { Strength } \\
\text { (Mpa) }\end{array}$ \\
\hline Neat ABS & $1.5 \pm 0.2$ & $52 \pm 0.8$ & $73 \pm 3$ \\
\hline $\begin{array}{l}\text { Expanded } \\
\text { ABS foam }\end{array}$ & $0.37 \pm 0.03$ & $9.2 \pm 0.7$ & $9.4 \pm 0.7$ \\
\hline
\end{tabular}

Table 2. Mechanical Performance of ABS Expanded Foam in Compression.

Note that in comparison to the selected syntactic foam performance, the mechanical performance of the expanded ABS foams offer significantly lower mechanical performance, but are also $\sim 30 \%$ of the density relative to the HGM foam. Compared to Neat ABS, the printable expanded foam achieves a density reduction of $\sim 80 \%$.

Other printable foam formulations were also developed for investigation in this application, but only the most printable foams were selected for mechanical testing. A summary of the possible foams both syntactic and expanded are included in Table 3.

Table 3. Recently developed printable low-density materials.

\begin{tabular}{|l|l|l|l|}
\hline \multicolumn{1}{|c|}{ Category } & \multicolumn{1}{|c|}{ Main composition } & Density & \multicolumn{1}{c|}{ Remarks } \\
\hline Syntactic Foam & ABS + CF + HGMs & $0.85 \mathrm{~g} / \mathrm{cc}$ & $\begin{array}{l}\text { Material scale-up is achieved by } \\
\text { compounding/pelletizing line of } \\
\text { industrial partner. }\end{array}$ \\
\hline Syntactic Foam & PA6 + CF + HGMs & $0.85 \mathrm{~g} / \mathrm{cc}$ & Semi-crystalline polymer matrix \\
\hline Syntactic Foam & PA12 + CF + HGMs & $0.78 \mathrm{~g} / \mathrm{cc}$ & Semi-crystalline polymer matrix \\
\hline $\begin{array}{l}\text { Expanding } \\
\text { foam }\end{array}$ & $\begin{array}{l}\text { ABS + CF with premixed } \\
\text { chemical blowing agent }\end{array}$ & $0.8 \mathrm{~g} / \mathrm{cc}$ & $\begin{array}{l}\text { Amorphous polymer matrix, the } \\
\text { density of the original ABS + 20 } \\
\text { wt.\% CF is 1.14 g/cc }\end{array}$ \\
\hline $\begin{array}{l}\text { Expanding } \\
\text { foam }\end{array}$ & $\begin{array}{l}\text { ABS + CF with expandable } \\
\text { spheres }\end{array}$ & $0.3 \mathrm{~g} / \mathrm{cc}$ & Amorphous polymer matrix \\
\hline $\begin{array}{l}\text { Expanding } \\
\text { foam }\end{array}$ & $\begin{array}{l}\text { PA6 with expandable } \\
\text { spheres }\end{array}$ & $0.3 \mathrm{~g} / \mathrm{cc}$ & Semi-crystalline polymer matrix \\
\hline $\begin{array}{l}\text { Expanding } \\
\text { foam }\end{array}$ & $\begin{array}{l}\text { PA12 with expandable } \\
\text { spheres }\end{array}$ & $0.3 \mathrm{~g} / \mathrm{cc}$ & Semi-crystalline polymer matrix \\
\hline
\end{tabular}

Compatibility with these formulations and the Low-E polymer films were not evaluated because of film unavailability. All polymers tested are less than $\$ 2.50$ per $\mathrm{kg}$.

\subsection{IMPACTS}

This project contributes to the DOE mission areas of the Advanced Manufacturing and Building Technologies through energy consumption reductions. Windows are responsible for about $11 \%$ of the energy that existing buildings consume, resulting in an annual economic impact in the US of more than $\$ 50$ billion. Despite the immense costs, the retrofit of windows has been slow. The primary reason is long payback periods. Replacing windows is labor intensive, and low-e glass storm windows only have thermal performance of up to R-4. The cost of replacement windows and low-e glass storm windows is particularly high because of customization costs due to the vast range of sizes and shapes of existing 
windows. This project helped accelerate adoption in the window retrofit market by developing a low epolymer window system that is light weight and easy to install, costs less than $25 \%$ of a full window replacement, achieves R-values as high as R-13, and has a payback time of 5 years or less.

\subsubsection{SUBJECT INVENTIONS}

There are no subject inventions that resulted from this project.

\subsection{CONCLUSIONS}

This project developed materials that addressed the required cost and mechanical requirements of Mackinac's window inserts.

BAAM technology was used to test the materials outlined in this report, which is useful as the need to customize the shapes and sizes of the window inserts will apply to every building the inserts are installed in. The use of printable foams to fabricate the frames is also preferable because of reduced mass, improved thermal insulation value, and compatibility with thin polymer films.

In summary the material solution outlined provides a feasible path forward for the production of high-performance and low-cost custom window inserts for retrofit in pre-existing buildings.

However, inserts produced lacked the aesthetic quality and performance necessary to be immediately applicable to the industry. Future investigation will be needed after improvements have been made in the BAAM multi-material capabilities and the ability to print with finer resolution. 


\section{THE MACKINAC TECHNOLOGY COMPANY BACKGROUND}

The Mackinac Technology Company was established in 2009 by founder and current CEO John Slagter. Soon after its founding, Mackinac began to develop a thin-film coating technology that is highly transparent to visible light, but highly reflective to infrared heat energy. The work was significant enough that by 2011 Mackinac had already won first place in the Advanced Materials Category of the Accelerate Michigan Innovation Competition. Mackinac's proprietary coating, when applied to polymer sheets, is the heart of a Window Energy Management System (WEMS) being developed, a system that aims to improve the energy efficiency of windows such that they have the same $R$ value as a wall ( $R$ value is a term that describes the ability of an insulating material to resist heat flow with a higher number being better than a lower number). Mackinac's low emissivity (low-e) polymer film technology uses amorphous diamond-like carbon materials, reflects infrared heat energy and is highly transparent to visible light. It's tough, durable and can be produced at much lower costs than conventional low-e technologies. It also has a patent pending. Mackinac also was a finalist in the 2016 Michigan's Governor's Energy Excellence Awards in the innovator of the year category.

Funding includes a \$2.5 million grant from the U.S. Department of Energy's Advanced Research Projects Agency-Energy or ARPA-E which funds innovative technologies that display promise for both technical and commercial impact but are too early for private-sector investment. Mackinac Technology was one of 41 projects to receive funding. 